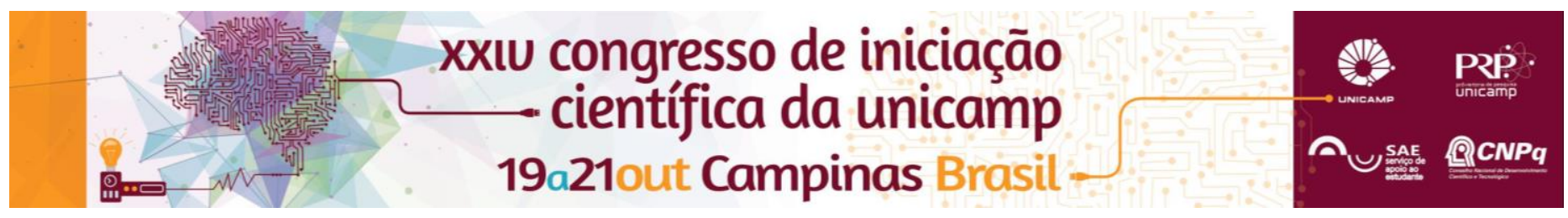

\title{
Utilização de séries temporais para previsão de material particulado (MP10)
}

\author{
Nathalia M. Rissi, Marla Rubia G. de Lima, Danilo C. Nogarotto, Simone A. Pozza.
}

\begin{abstract}
Resumo
Poluente atmosférico é toda e qualquer forma de matéria ou energia presente no ar que posso torná-lo improprio, nocivo ou ofensivo à saúde, tendo a capacidade de pôr em risco fauna e a flora. O estudo na ênfase de MP é de vital importância pois é um dos principais poluentes atmosféricos. Foram obtidas concentrações diárias de MP10 no Sistema QUALAR da CETESB, referente aos município de Campinas, Jundiaí, Paulinía e Piracicaba. Tais dados foram tratados com o intuito de prever concentrações futuras de MP10. Como método estatístico para manipulação destes dados optou-se por modelos de séries temporais utilizando-se de modelos ARIMA e SARIMA. Os resultados mais satisfatórios foram obtidos pelo modelo SARIMA, pois apresentou os melhores ajustes em relação aos parâmetros estabelecidos.
\end{abstract}

\section{Palavras-chave:}

Séries temporais, MP10, Poluição atmosférica.

\section{Introdução}

A poluição do ar é caracterizada pela presença de uma ou mais substâncias químicas com concentrações suficientes para causarem danos aos seres humanos, animais, vegetais, ou em materiais. Para o tratamento de dados dos monitoramentos desses poluentes, contamos com ferramentas matemáticas e estatísticas, que auxiliam nas análises e estudo de seu comportamento. Atualmente, tem sido utilizada por diversos autores a análise de séries temporais no estudo do comportamento das variáveis poluentes, especificamente o MP, ao longo do tempo. Este trabalho teve como objetivo utilizar modelos de séries temporais para realizar previsões de possíveis valores futuros da concentração de $\mathrm{MP}_{10}$ das cidades do interior de São Paulo, Campinas, Jundiaí, Paulínia e Piracicaba, visando encontrar padrões de tendência, bem como a existência de variação sazonal ou cíclica e alterações estruturais. Para isso foi necessário dados diários da concentração de $\mathrm{MP}_{10}$ dos anos de 2010 a 2014 que foram obtidos na plataforma QUALAR da CETESB.

\section{Resultados e Discussão}

Para realizar a previsão dos dados foram identificados diversos modelos ARIMA (A) e SARIMA (S) a fim de comparar qual obteve melhores resultados. Para isso utilizamos os valores de AIC (Critério de Informação Akaike), LOG (Log-verossimilhança) e EQM (erro quadrático médio de previsão). Este último foi calculado baseado na previsão dos próximos 30 dias (janeiro de 2015). As medidas do AIC e EQM são melhores quando os valores são menores. Já o LOG, quanto maior, melhor. Para identificar os modelos foram analisadas as funções de auto correlação (fac) e as funções de auto correlação parcial (facp). Nos modelos SARIMA considerou-se a sazonalidade com um período de sete dias, isto supondo que concentrações de MP10 podem ter comportamentos similares no mesmo dia da semana. O modelo a ser escolhido para realizar a previsão do MP10, vai depender do melhor resultado em relação aos parâmetros. Nas cidades de Campinas, Jundiaí (tabela 1) e Paulínia (tabela 2), não houve um ajuste que obteve mais de um parâmetro melhor em relação aos outros, porém em Piracicaba o modelo $S(2,0,2) \times(2,0,2)$ foi o que obteve menor AIC, e maior LOG.
Tabela 1. Valor do AIC LOG e EQM da cidade de Campinas e Jundiaí.

\begin{tabular}{|c|c|c|c|c|c|c|c|}
\hline & \multicolumn{4}{|c|}{ Campinas } & \multicolumn{3}{|c|}{ Jundiai } \\
\hline & S & AIC & LOG & EQM & AIC & LOG & EQM \\
\hline$A(1,0,2) \times(0,0,0)$ & 0 & 1399,32 & $-694,66$ & 0,40 & 1399,32 & $-694,66$ & 0,40 \\
\hline$S(1,0,2) \times(1,0,2)$ & 7 & 1355,11 & $-669,56$ & 0,40 & 1355,11 & $-669,56$ & 0,40 \\
\hline$S(1,0,1) \times(1,0,1)$ & 7 & 1352,31 & 670,16 & 0,40 & 1352,31 & $-670,16$ & 0,40 \\
\hline$S(2,0,2) \times(2,0,2)$ & 7 & 1321,60 & $-650,80$ & 0,42 & 1321,60 & $-650,80$ & 0,42 \\
\hline$A(2,0,2) \times(0,0,0)$ & 0 & 1369,29 & $-678,65$ & 0,42 & 1369,29 & $-678,65$ & 0,42 \\
\hline$S(1,1,2) \times(1,0,2)$ & 7 & 1328,46 & $-657,23$ & 0,44 & 1328,46 & $-657,23$ & 0,44 \\
\hline$S(1,1,1) \times(1,0,1)$ & 7 & 1362,88 & $-676,44$ & 0,40 & 1362,88 & $-676,44$ & 0,40 \\
\hline$S(1,1,1) \times(1,1,1)$ & 7 & 1358,34 & $-674,17$ & 0,43 & 1358,34 & $-674,17$ & 0,43 \\
\hline
\end{tabular}

Tabela 2. Valor do AIC LOG e EQM da cidade de Paulínia e Piracicaba.

\begin{tabular}{|c|c|c|c|c|c|c|c|}
\hline & \multicolumn{4}{|c|}{ Paulínia } & \multicolumn{3}{|c|}{ Piracicaba } \\
\hline & $\mathbf{S}$ & AIC & LOG & EQM & AIC & LOG & EQM \\
\hline$A(1,0,2) \times(0,0,0)$ & 0 & 1073,89 & $-531,94$ & 0,34 & 1419,19 & $-704,60$ & 0,45 \\
\hline$S(1,0,2) \times(1,0,2)$ & 7 & 981,40 & $-482,70$ & 0,32 & 1331,81 & $-657,91$ & 0,42 \\
\hline$S(1,0,1) \times(1,0,1)$ & 7 & 982,94 & $-485,47$ & 0,32 & 1331,25 & $-659,62$ & 0,42 \\
\hline$S(2,0,2) \times(2,0,2)$ & 7 & 947,20 & $-463,60$ & 0,33 & 1275,53 & $-627,77$ & 0,42 \\
\hline$A(2,0,2) \times(0,0,0)$ & 0 & 1029,69 & $-508,85$ & 0,32 & 1364,42 & $-676,21$ & 0,41 \\
\hline$S(1,1,2) \times(1,0,2)$ & 7 & 950,22 & $-468,11$ & 0,36 & 1279,90 & $-632,95$ & 0,45 \\
\hline$S(1,1,1) \times(1,0,1)$ & 7 & 947,07 & $-468,53$ & 0,36 & 1279,38 & $-634,69$ & 0,45 \\
\hline$S(1,1,1) \times(1,1,1)$ & 7 & 964,48 & $-477,24$ & 0,36 & 1295,11 & $-642,55$ & 0,45 \\
\hline
\end{tabular}

\section{Conclusões}

Em geral os modelos SARIMA apresentaram resultados mais satisfatórios quando comparados aos ARIMAs. Há evidências que a série temporal do MP10 tem um comportamento de memória longa, por isso a previsão não é tão precisa. Como sugestão de trabalho futuro talvez o melhor modelo que se encaixe nessa situação seja os modelos ARFIMA (Modelo Auto Regressivo Fracionário Integrado de Médias Móveis).

\section{Agradecimentos}

Ao Conselho Nacional de Desenvolvimento Científico e Tecnológico (CNPq), pela concessão da bolsa de Iniciação Científica e ao QUALAR (Qualidade do Ar) pela disponibilidade dos dados utilizados para o estudo. 